\title{
ANALISIS REKRUTMEN PEGAWAI DAN DAMPAKNYA PADA TINGKAT PENGANGGURAN DI KOTA PONTIANAK
}

\author{
JONATHAN GIOVANNI', FRANSISKA EKOBELAWATI \\ ign.jonathangiovanni@gmail.com \\ ${ }^{1}$ Universitas Palangka Raya \\ ${ }^{2}$ Akademi Sekretari Manajemen Indonesia Pontianak
}

\begin{abstract}
The research was made by looking at the phenomenon of the growth in the number of businesses in 2017, there were more than 6,500 (six thousand five hundred) new business entities formed in Pontianak City which indirectly also affected Pontianak City's Gross Regional Domestic Product (PDRB) according to the business field in 2018 which an increase of 5.05 percent from the previous year. However, in reality on the ground, according to the release of data by BPS Pontianak City in 2018, it shows that the open unemployment rate in 2018 was 10.37 percent, up 1.04 percent compared to 2017. This is very contrary to the previous fact where the agency business continues to increase in Pontianak City. This study will dig deeper into the role of businesses, especially in the trade sector, in attracting prospective employees as an effort to reduce unemployment in Pontianak City. The data were obtained through questionnaires and interviews with business people, of course, by prioritizing health protocols. The results showed that the biggest problem with the increase in the unemployment rate in Pontianak City was the interest of business actors to seek workers from outside the Pontianak City area which prevented the existing workforce from being absorbed. inside the city of Pontianak.
\end{abstract}

Keywords: recruitment, labor, Pontianak

\begin{abstract}
ABSTRAK
Penelitian dibuat dengan melihat fenomena adanya pertumbuhan jumlah usaha tahun 2017 tercatat lebih dari 6.500 (enam ribu lima ratus) badan usaha baru terbentuk di Kota Pontianak yang secara tidak langusng juga mempengaruhi Produk Domestik Regional Bruto (PDRB) Kota Pontianak menurut lapangan usaha pada tahun 2018 yang meningkat 5,05 persen dari tahun sebelumnya. Namun pada kenyataan di lapangan menurut rilis data oleh BPS Kota Pontianak tahun 2018 menunjukkan bahwa tingkat pengangguran terbuka pada tahun 2018 adalah sebesar 10,37 persen, naik 1,04 persen dibandingkan dengan tahun 2017. Hal ini menjadi sangat bertolak belakang dengan fakta sbelumnya dimana badan usaha terus bertambah di Kota Pontianak. Penelitian ini akan menggali lebih dalam peran usaha terutama pada sektor perdagangan dalam menarik calon karyawan sebagai usaha mengurangi tingkat
\end{abstract}


pengangguran di Kota Pontianak. Data diperoleh melalui kuisioner dan wawancara rekrutmen, tenaga kerja,

Pontianak dengan para pelaku usaha tentu dengan tetap mengedepankan protocol kesehatan.hasil penelitian menunjukan bahwa masalah terbesar meningkatnya tingkat pengangguran di Kota Pontianak adalah ketertarikan para pelaku usaha untuk mencari pekerja dari luar daerah Kota Pontianak yang membuat tidak terserapnya tenaga kerja yang ada di dalam Kota Pontianak.

Kata Kunci: rekrutmen, tenaga kerja, Pontianak

\section{PENDAHULUAN}

Produk Domestik Regional Bruto (PDRB) Kota Pontianak menurut lapangan usaha pada tahun 2018 meningkat 5,05 persen dari tahun sebelumnya dengan kontribusi terbesar berasal dari sector lapangan usaha perdagangan baik besar dan eceran. Data ini juga didukung dengan adanya peningkatan jumlah usaha pada sector perdagangan di Kota Pontianak (Badan Pusat Statistik Kota Pontianak, 2019).

Sejak tahun 2013 sampai tahun 2017 tercatat lebih dari 6.500 (enam ribu lima ratus) badan usaha baru terbentuk di Kota Pontianak (Badan Pusat Statistik Kota Pontianak, 2018). Data lebih rinci dapat dilihat pada tabel 1.1. Perkembangan jumlah badan usaha yang semakin banyak secara langsung sebagai dapat menggambarkan membaiknya iklim perekonomian di Kota Pontianak.

Tabel 1

Jumlah Perusahaan yang Baru Berdiri Menurut Bentuk Badan Hukum

\begin{tabular}{|l|c|c|c|c|c|}
\hline \multirow{2}{*}{ Bentuk Badan Hukum } & \multicolumn{5}{|c|}{ Jumlah Perusahaan yang Baru Berdiri } \\
\cline { 2 - 6 } & 2013 & 2014 & 2015 & 2016 & 2017 \\
\hline PT & 32 & 445 & 572 & 383 & 396 \\
\hline CV/Firma & 73 & 602 & 678 & 539 & 520 \\
\hline Koperasi & 2 & 5 & 14 & 18 & 12 \\
\hline Perorangan & 349 & 470 & 533 & 472 & 391 \\
\hline Perusahaan Dagang & 2 & 45 & 47 & 43 & 28 \\
\hline Lainnya & 2 & 5 & 11 & 3 & 2 \\
\hline Jumlah & 460 & 1572 & 1855 & 1458 & 1349 \\
\hline
\end{tabular}

Sumber : (Badan Pusat Statistik Kota Pontianak, 2018)

Tingkat pertumbuhan usaha sector perdagangan ini harusnya akan mampu menyerap tenaga kerja yang lebih banyak dan secara langsung akan mengurangi tingkat penganguran terbuka. Tingkat Penganguran Terbuka (TPT) merupakan persentase 
pengangguran terhadap angkatan kerja (Badan Pusat Statistik Kota Pontianak, 2019). rekrutmen, tenaga kerja,

Pontianak TPT dapat digunakan sebagai indikator tingkat penggunaan dan penyerapan tenaga kerja. Tingkat TPT kurang dari 4 persen menunjukkan bahwa tingkat pengangguran masih dalam tingkat normal.

Namun pada kenyataan di lapangan menurut rilis data oleh BPS Kota Pontianak tahun 2018 menunjukkan bahwa tingkat pengangguran terbuka pada tahun 2018 adalah sebesar 10,37 persen, naik 1,04 persen dibandingkan dengan tahun 2017. Hal ini menjadi sangat bertolak belakang dengan fakta sbelumnya dimana badan usaha terus bertambah di Kota Pontianak. Berbeda dengan data pertumbuhan ekonomi Kota Pontianak yang terus menunjukkan perkembangan positif, tingkat pengangguran justru sebaliknya dimana sejak tahun 2013 sampai tahun 2017 terus mengalami performa buruk, dimana tingkat pengangguran Kota Pontianak selalu berada di atas nilai 6 persen. Data lebih lengkap dapat dilihat pada grafik 1.1 di bawah ini.

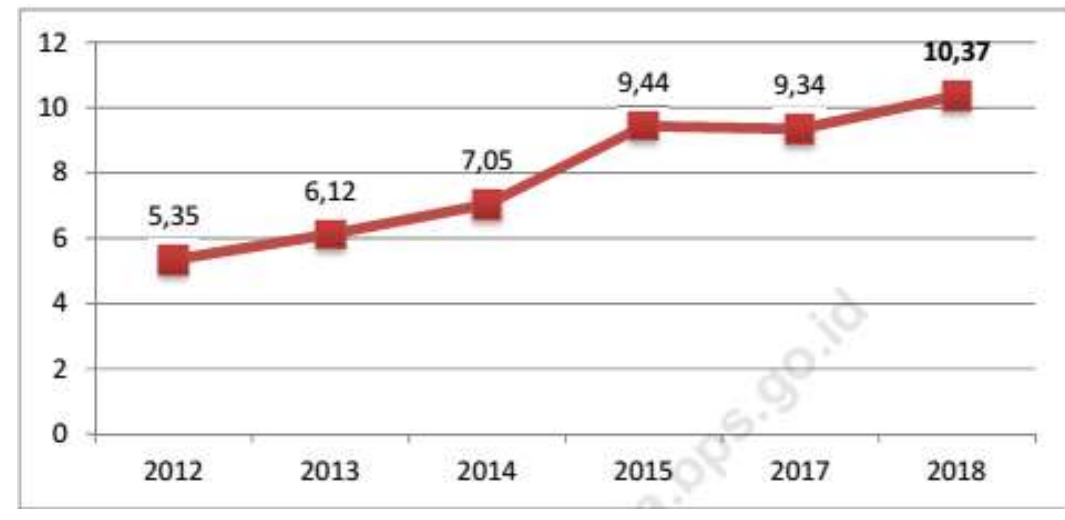

Grafik 1

Prosentase Tingkat Pengangguran Terbuka Kota Pontianak tahun 2012 - 2018 (BPS Kota Pontianak, 2019)

Perubahan tingkat pengangguran akan sangat dipengaruhi oleh system penarikan pegawai yang dilakukan oleh badan badan usaha secara khusus sector perdagangan yang ada di Kota Pontianak. Bagaimana system dan kriteria para pelaku usaha dalam menarik karyawan ke dalam perusahannya akan menjadi factor yang krusial dalam perubahan tingkat pengangguran. Bagaimana ketertarikan para pelaku usaha terhadap ketersediaan sumber daya manusia yang ada di Kota Pontianak akan menjadi hal yang menarik untuk ditelusuri. Begitu juga dari sisi sebaliknya pakah kualitas sumber daya manusia yang tersedia di Kota Pontianak ini sudah mampu memenuhi kebutuhan yang 
diinginkan oleh para pelaku usaha. Penelitian ini pada akhirnya akan menjadi gambaran rekrutmen, tenaga kerja, awal penyebab munculnya angka pengangguran di Kota Pontianak.

\section{TINJAUAN PUSTAKA}

\section{Tenaga Kerja}

Tenaga kerja merupakan salah satu faktor produksi yang dinilai sangat penting untuk mengolah sumber daya yang lainnya. Penduduk yang sedang atau yang sudah bekerja, sedang mencari pekerjaan dan yang melakukan kegiatan-kegiatan lain, seperti bersekolah dan mengurus rumah tangga dapat dikategorikan sebagai tenaga kerja. Tenaga kerja stidak - tidaknya berusia 10 tahun hingga tanpa batas umur maksimum (Simanjuntak, 2005).

Tenaga kerja lebih spesifik dijelaskan oleh Badan Pusat Statitik (BPS) yang menyatakan bahwa bahwa penduduk yang berada dalam usia siap kerja yaitu berumur 15 tahun ke atas, baik yang siudah bekerja, yang tidak bekerja, maupun yang sedang mencari pekerjaan atau lebih dikenal sebagai penduduk angkatan kerja. Namun Tjiptoherijanto (2001), dalam penelitiannya menyimpulkan juga bahwa usia 10 sampai 14 tahun dapat disebut penduduk yang terpaksa bekerja. Kedua batasan di atas dapat menyimpulkan bahwa yang termasuk dalam angkatan kerja adalah penduduk yang berusia 10 tahun ke atas baik yang sedang bekerja maupun yang sedang mencari pekerjaan.

\section{Rekrutmen}

Rekrutmen adalah sebuah rangkaian proses dalam menentukan dan menarik calon pegawai yang dinilai mampu untuk bekerja dalam sebuah organisasi usaha. Rekrutmen dimulai organisasi mulai mencari para calon pegawai dan berakhir ketika mereka memberi respond an mebawa dan menyerahkan lamaran - lamaran mereka. Hasil akhir dari proses ini adalah sekumpulan pelamar calon pegawai yang kemudian akan dilakukan proses seleksi untuk kemudian dipilih (Rivai, 2013).

Rekrutmen sering diberlakukan seolah-olah sebagai suatu proses satu arah (oneway process) yaitu sesuatu yang dilakukan perusahaan untuk mencari karyawan, atau yang dikenal dengan teori rekrutmen "pencarian" (prospecting theori of rekruitment) 
dan calon karyawan dan manager mencari organisasi bagaimana halnya organisasi tenaga kerja,

Pontianak mencari mereka, pandangan ini disebut dengan teori rekrutmen "pasangan" (mating theory of recruitment) (Henry, 2003).

Keberhasilan rekrutmen dan keberhasilan pencarian pekerjaan, keduanya tergantung pada waktunya. Bilamana terdapat kecocokan antara upaya rekrutmen organisasional dengan upaya pencarian kerja pelamar, maka kondisinya dalam keadaan matang untuk bertemu. Menyediakan bagi organisasi sekelompok calon pegawai yang mampu selaras dengan tujuan organisasi adalah tujuan utama yang ingin dicapai dalam proses rekrutmen.

\section{Pengangguran Terbuka}

Pengangguran terbuka adalah persentase penduduk dalam angkatan kerja yang tidak memiliki pekerjaan dan sedang mencari pekerjaan. Masalah pengangguran dalam suatu daerah secara langsung dapat berdampak pada tingkat pendapatan nasional dan tingkat kemakmuran masyarakat yang pada kemudian hari akan menimbulkan masalah pokok makro ekonomi yang paling utama (Badan Pusat Statistik Kota Pontianak, 2019).

Berdasarkan pendekatan angkatan kerja membagi pengangguran menjadi tiga jenis, yaitu (Saputra, 2011):

a. Pengangguran friksional.

Pengangguran jenis ini adalah pengangguran yang muncul karena pencari kerja masih mencari pekerjaan yang sesuai jadi ia menganggur bukan karena tidak ada pekerjaan. Pengangguran ini tidak menimbulkan masalah, dan bisa diselesaikan dengan pertumbuhan ekonomi.

b. Pengangguran struktural

Pengangguran struktural adalah pengangguran yang muncul karena perubahan struktur dan komposisi perekonomian. Pengangguran ini sulit diatasi karena terkait dengan strategi pembangunan sebuah negara. Meskipun demikian, pengangguran jenis ini bisa diatasi dengan melakukan pelatihan agar tercipta tenaga kerja terampil.

c. Pengangguran musiman.

Pengangguran yang terjadi karena faktor musim, misalnya para pekerja di industri yang mengandalkan hidupnya dari pesanan. Pengangguran jenis ini juga tidak 
menimbulkan banyak masalah. Meskipun belum ada bukti empirik yang rekrutmen tenaga kerja, mendukung, pengangguran yang muncul karena keterpurukan industri sebagian besar adalah pengangguran friksional dan struktural. Pengangguran friksional yang muncul di Indonesia tidak karena menganggur secara "sukarela" melainkan karena kondisi krisis ekonomi

\section{METODE PENELITIAN}

\section{Definisi Operasional Variabel}

Definisi operasional yang digunakan pada penelitian ini adalah Pola Rekrutmen Para pelaku usaha sekrtor perdagangan di Kota Pontianak (X) yaitu berupa preferensi organisasi tersebut dalam mencari dan merekrut calon pegawai yang secara khusus pada badan usaha bentuk PT dan CV/Firma. Tingkat Pengangguran terbuka (Y) adalah tingkat angkatan kerja yang sedang mencari pekerjaan dan belum mendapat pekerjaan di Kota Pontianak.

\section{Jenis Dan Sumber Data}

Penelitian ini menggunakan jenis data deskriptif dimana data akan diperoleh berdasarkan publikasi BPS Kota Pontianak yaitu data demografi penduduk terutama dalam sector pendidikan dan data ketenagakerjaan yang khususnya tingkat pengangguran terbuka mulai tahun 2013 - 2018. Data selanjutnya akan dianalisis bersama dengan hasil kuisioner yang diberikan pada narasumber.

\section{Bentuk Penelitian}

Metode deskriptif digunakan untuk menggambarkan sifat suatu masalah yang sedang berlangsung pada saat penelitian dengan memeriksa sebab - sebab dari suatu gejala tertentu (Sugiyono, 2017). Tujuan dari penelitian deskriptif ini adalah untuk membuat deskriptif, gambaran, atau lukisan secara sistematik, faktual, dan akurat mengenai fakta-fakta, sifat-sifat, serta hubungan antar fenomena yang diselidiki. 


\section{Variabel Penelitian}

Variabel Penelitian adalah suatu konsep atau objek yang telah yang ditetapkan oleh peneliti untuk diteliti atau di uji kebenarannya dari hasil penelitian tersebut. Variabel penelitian ini adalah pola rekrutmen dan tingkat pengangguran terbuka.

\section{Teknik Pengumpulan Data}

Pengumpulan data diperoleh dari data yang telah dirilis oleh BPS Kota Pontianak Tahun 2013 sampai dengan 2018. Yang kemudian akan di analisis lebih mendalam bersama dengan data hasil dari kuisioner yang akan diberikan kepada para pelaku usaha pada sektor perdagangan di Kota Pontianak

\section{Populasi dan Sampel}

Populasi dalam penelitian ini adalah badan usaha PT dan CV/Firma pada sektor perdagangan yang baru terbentuk pada tahun 2013 - 2018 di Kota Pontianak. Sampai pada tahun 2018 terdapat sekitar 6.600 badan usaha baru yang terbentuk diantaranya adalah badan usaha berbentuk PT sebanyak 1.828 badan usaha sementara CV/Firma sebanyak 2.412 (Badan Pusat Statistik Kota Pontianak, 2019). Sampel adalah sebagian dari jumlah dan karakteristik yang dimiliki oleh populasi tersebut (Sugiyono, 2017). Penelitian ini menggunakan teknik probability sampling secara simple random sampling dimana badan usaha terpilih secara acak. Jumlah sampel yang akan digunakan sebesar 100 sampel.

\section{HASIL PENELITIAN}

Data yang didapat pada penelitian ini didapat dari para pelaku usaha pada sector perdagangan seperti pengusaha makanan siap saji, sembako, dan yang lainnya. Narasumber yang terjaring berumur 20 - 35 tahun sebesar $50 \%$ dan lebih dari 35 tahun sebesar $50 \%$ dari total 100 responden yang didapatkan dimana sebanyak $61 \%$ pelaku usaha tersebut sudah menjalankan usahanya lebih dari 3 tahun.

Hasil penelitian ini memberikan hasil yang sangat menarik tentang bagaimana pola ketertarikan para pelaku usaha terhadap tenaga kerja yang ada di Kota Pontianak. Data pertama berdasarkan ketertarikan jenis kelamin, sebanyak $53 \%$ responden lebih 
tertarik untuk merekrut karyawan berjenis kelamin laki-laki. Hal ini berkaitan dengan rekrutmen, tenaga kerja, jam kerja yang mayoritas adalah lebih dari 35 jam dalam satu minggu sehingga membutuhkan tenaga yang lebih besar dimana dianggap laki - laki yang memiliki tenaga lebih besar. Dalam hal ini sebetulnya pola rekrutmen yang dilakukan para pelaku usaha di Kota Pontianak harusnya mampu menurunkan tingkat pengangguran karena berdasarkan data statistik ketenagakerjaan Kota Pontianak yang dirilis oleh BPS Kota Pontianak tahun 2019 sebanyak 66,34 \% pengangguran di Kota Pontianak adalah laki-laki. Maka dalam hal ini pola rekrutmen yang dilakukan oleh para pelaku usaha sebenarnya sudah mampu berkontribusi dalam penurunan angka pengangguran di Kota Pontianak.

Aspek kedua yang dilihat dalam penelitian ini adalah status perkawinan calon karyawan. Hasil yang didapat pada aspek ini mendukung apa yang ditunjukkan pada aspek pertama sebelumnya. Sebanyak $81 \%$ para pelaku usaha lebih tertarik dengan calon karyawan yang elum menikah. Beberapa alasan yang telah dungkapkan adalah berkaitan dengan pemberian gaji dan waktu kerja. Karyawan yang belum menikah maka tidak memiliki tanggungan yang besar sehingga dalam pemberian gaji juga lebih fleksibel bagi para pelaku usaha sementara dari jam kerja juga karyawan yang belum menikah memiliki kelaluasaan jam kerja terutama dalam hal lembur. Hasil ini sebetulnya juga menunjukkan bahwa pola rekrutmen yang dilakukan para pelaku usaha di Kota Pontianak seharusnya mampu menurunkan tingkat pengangguran karena berdasarkan data statistik ketenagakerjaan Kota Pontianak yang dirilis oleh BPS Kota Pontianak tahun 2019 sebanyak 68,60 \% pengangguran di Kota Pontianak berstatus belum kawin. Maka dalam hal ini pola rekrutmen yang dilakukan oleh para pelaku usaha sebenarnya sudah mampu berkontribusi dalam penurunan angka pengangguran di Kota Pontianak.

Aspek ketiga yang dilihat dari penelitian ini adalah pendidikan. Data menunjukkan bahwa para pelaku usaha sebanyak 89 \% lebih menyukai calon karyawan yang memiliki ijazah SMA/SMK. Beberapa hal yang diungkapkan oleh para pelaku usaha ini adalah di tingkat SMA/SMK para calon karyawan sudah memiliki kemampuan yang cukup baik fisik maupun psikis untuk bekerja dan juga dari segi pemberian gaji standar calon karyawan yang memiliki ijazah SMA/SMK dapat dijangkau oleh para 
pengusaha. Sementara untuk yang bergelar sarjana para responden berasumsi bahwa sudah memiliki standar yang tinggi sehingga sulit untuk menetapkan standar pembayaran. Hasil ini sebetulnya juga mendukung apa yang terjadi di aspek pertama dan kedua dimana seharusnya mampu menurunkan tingkat pengangguran karena berdasarkan data statistik ketenagakerjaan Kota Pontianak yang dirilis oleh BPS Kota Pontianak tahun 2019 sebanyak 48,3 \% pengangguran di Kota Pontianak adalah masyarakat yang memiliki ijazah SMA/SMK. Maka dalam hal ini pola rekrutmen yang dilakukan oleh para pelaku usaha sebenarnya sudah mampu berkontribusi dalam penurunan angka pengangguran di Kota Pontianak.

Aspek keempat yang dilihat dalam penelitian ini adalah pengalaman kerja. Berdasarkan data primer yang didapat sebanyak $88 \%$ para pelaku usaha lebih tertarik untuk merekrut calon karyawan yang sudah memiliki pengalaman kerja karena mereka beranggapan bahwa calon masyarakat yang seperti ini sudah siap bekerja tapa perlu adaptasi pekerjaan yang lama. Hal ini cukup bertolak belakang dengan keadaan yang ada. Berdasarkan data tingkat pengangguran di Kota Pontianak sebanyak 33,9 \% pengangguran yang ada berada pada usia 15 - 24 tahun dimana ini sebenarnya adalah usia sekolah tetapi mereka memilih untuk bekerja yang secara langsung akan memunculkan tenaga kerja yang belum memiliki pengalaman. Hal ini berbeda sekali dengan yang didapat pada tiga spek sebelumnya dimana aspek ini dapat memperlihatkan adanya kecenderungan para pelaku usaha tidak mampu menyerap tenaga kerja baru yang belum pengalaman tetapi hanya mencari tenaga kerja yang sudah berpengalaman.

Aspek terakhir atau yang kelima dalam penelitian ini adalah asal daerah tenaga kerja. Hasil ini menjadi hasil yang paling memberikan signifikan mengapa tingkat pengangguran di Kota Pontianak masih tinggi. Hasil yang didapat adalah 53\% para pelaku usaha lebih tertarik untuk mencari pekerja yang berasal dari luar Kota Pontianak. Hasil ini memberi tanda nyata mengapa angka pangangguran Kota Pontianak masih tinggi. Asumsi yang dikeluarkan adalah karena pekerja dari Luar Kota Pontianak dinilai memiliki semangat yang lebih baik. 


\section{Kesimpulan}

rekrutmen, tenaga kerja,

Pontianak

Penelitian ini menunjukkan tanda bahwa memang pelaku usaha terutama di sektor perdagangan yang ada di Kota Pontianak masih belum menunjukkan kontribus yang signifikan dalam penyerapan tenaga kerja. Terbukti dari ketertarikan mencari pekerja dari luar daerah uang lebih besar dibandingkan mencari pekerja dari dalam Kota Pontianak. Hal ini juga dapat memberikan masukan kepada Pemerintah Kota Pontianak agar dapat terus membekali para calon pemberi kerja dengan kemampuan yang dibutuhkan oleh dunia usaha sehingga dapat mengubah ketertarikan para pelaku usaha untuk menarik calon tenaga kerja dari dalam Kota Pontianak.

\section{DAFTAR PUSTAKA}

Badan Pusat Statistik Kota Pontianak. (2018). Statistik Ketenagakerjaan Kota Pontianak 2018.

Badan Pusat Statistik Kota Pontianak. (2019). Pontianak City by Number or Kota Pontianak Dalam Angka 2019. In Pontianakkota.Go.Id (2019th ed.). BPS Kota Pontianak.

Henry, S. (2003). Manajemen Sumber Daya Manusia In Manajemen Sumber Daya Manusia. In Edisi Revisi Jakarta: Bumi Aksara.

Rivai, V. (2013). Manajemen Sumber Daya Manusia. Manajemen Sumber Daya Manusia Untuk Perusahaan Dari Teori Ke Praktik.

Saputra, A. W. (2011). Analisis Pengaruh Jumlah Penduduk, PDRB, IPM, Pengangguran Terhadap Tingkat Kemiskinan Di Kabupaten / Kota Jawa Tengah. Jurnal Ekonomi Pembangunan.

Simanjuntak, P. J. (2005). Manajemen dan Evaluasi Kinerja. In FE UI.

Sugiyono. (2017). Metode Penelitian Bisnis (Pendekatan Kuantitatif, Kualitatif, Kombinasi dan R\&D). In Metodelogi Penelitian.

Tjiptoherijanto, P. (2001). Proyeksi Penduduk, Angkatan Kerja, Tenaga Kerja, dan Peran Serikat Pekerja dalam Peningkatan Kesejahteraan Prijono. Majalah Perencanaan Pembangunan. 